J. T. BINDER, C. J. CORDIER, G. C. FU* (MASSACHUSETTS INSTITUTE OF TECHNOLOGY, CAMBRIDGE AND CALIFORNiA INSTITUTE OF TECHNOLOGY, PASADENA, USA)

Catalytic Enantioselective Cross-Couplings of Secondary Alkyl Electrophiles with Secondary Alkylmetal Nucleophiles: Negishi Reactions of Racemic Benzylic Bromides with Achiral Alkylzinc Reagents J. Am. Chem. Soc. 2012, 134, 17003-17006.

\title{
Negishi Reaction of Racemic Benzylic Bromides and Alkylzinc Reagents
}

Gategory

Metal-Catalyzed

Asymmetric

Synthesis and

Stereoselective

Reactions

\section{Key words}

\section{nickel}

Negishi coupling oxazoline ligands<smiles>[C]1[CH]CCC1</smiles>

\section{$\mathrm{NiBr}_{2} \cdot$ glyme $(10 \mathrm{~mol} \%)$ ligand $(13 \mathrm{~mol} \%)$

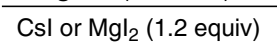 $\mathrm{CH}_{2} \mathrm{Cl}_{2}$-dioxane, $-30^{\circ} \mathrm{C}$}

Selected examples:

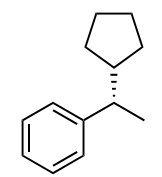

$95 \%$ yield, $91 \%$ ee

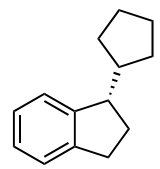

$96 \%$ yield, $74 \%$ ee

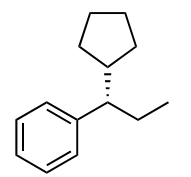

$93 \%$ yield, $84 \%$ ee

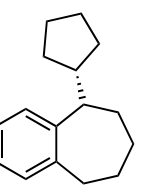

$98 \%$ yield, $79 \%$ ee
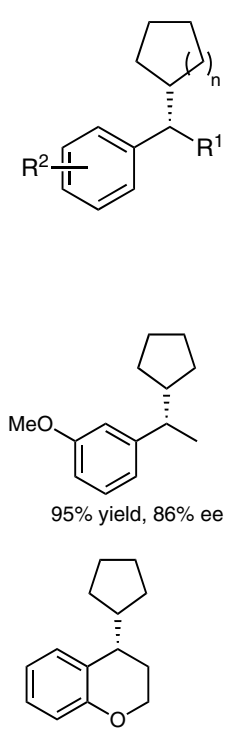

$95 \%$ yield, $54 \%$ ee
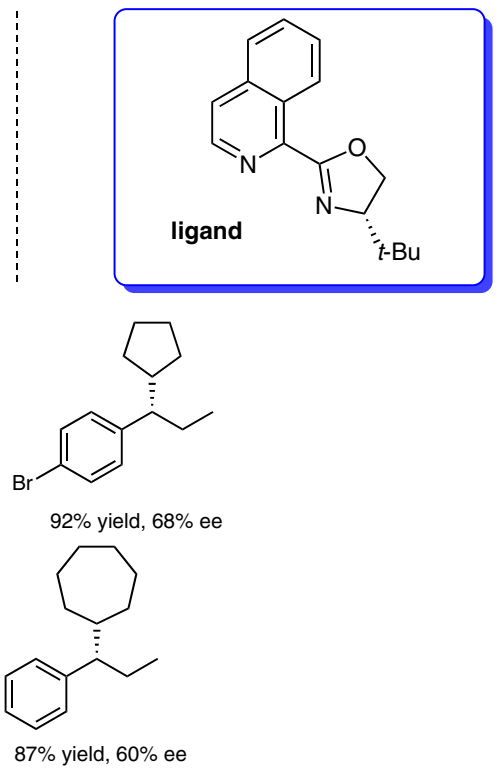

For acyclic alkylzinc reagents:

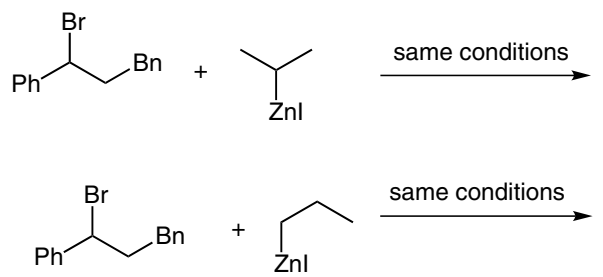

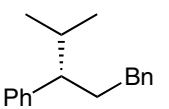

(76

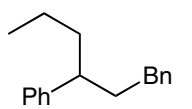

24)

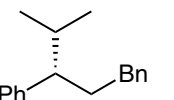

branched $76 \%$ ee linear $9 \%$ ee linear $9 \%$ ee branched $59 \%$ ee<smiles>CCC[C@H](CBr)c1ccccc1</smiles>

$(62$
38)

Proposed mechanism:

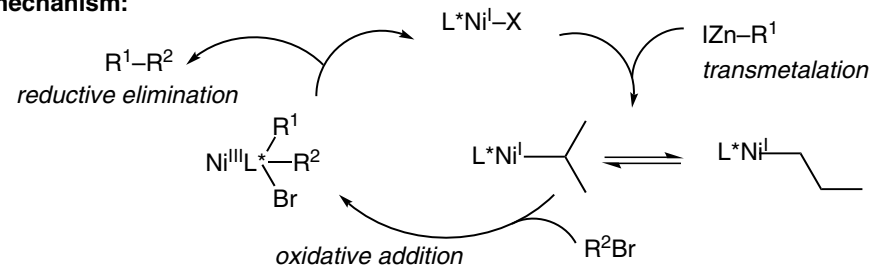

Significance: Reported here is an enantioselective cross-coupling of racemic benzylic bromides with achiral alkylzinc reagents. A novel bidentate oxazoline-type ligand was developed, leading to the desired products in good yield and enantioselectivity.
Comment: It is surprising that both reagents are achiral. For acyclic alkylzinc reagents, an usual isomerization was observed and a substantial amount of a branched product was generated from an unbranched nucleophile.

SYNFACTS Contributors: Hisashi Yamamoto, Jiajing Tan

Synfacts 2013, 9(1), 0073 Published online: 17.12.2012

Dol: 10.1055/s-0032-1317780; Reg-No.: H16012SF 